\title{
Loomislugu filosoofias: hr Berkeley vastus Lady Percivalile
}

\author{
Roomet Jakapi \\ Tartu Ülikooli filosoofia ajaloo kaasprofessor \\ roomet.jakapi@ut.ee
}

\begin{abstract}
Teesid: Artiklis vaadeldakse Esimeses Moosese raamatus sisalduva loomisloo metafüüsilist käsitlust iiri filosoofi George Berkeley teoses "Kolm dialoogi Hylase ja Philonousi vahel” (1713). Kompleksse filosoofilise konstruktsiooni abil selgitab Berkeley, et tema idealistlik süsteem ei ole pühakirjaga vastuolus. Näitan, et Berkeley eksegees on siinkohal sõnasõnaline ja toob nähtavale tema filosoofilise platonismi. Selgitan, kuidas selles metafüüsilises piiblitõlgenduses ilmneb filosoofia ja ilmutusreligiooni keerukas suhe 18. sajandi algul.
\end{abstract}

Märksõnad: Berkeley, filosoofia ajalugu, ilmutusreligioon, loomislugu, varauusaeg

\section{Sissejuhatus}

1710. aastal avaldas iiri filosoof George Berkeley (1685-1753) teose "Traktaat inimtunnetuse printsiipidest", mille keskmes on väide, et mateeriat ei ole olemas. Selline tees põhjustas publikus pigem hämmingut, naeru ja võõristust kui soovi süveneda ja sisukalt diskuteerida. ${ }^{1}$

Berkeley teadmata võttis tema idealistliku metafüüsika suhtes aga võrdlemisi positiivse hoiaku Gottfried Wilhelm Leibniz (1646-1716), kes oli samuti idealist. Leibniz kiitis heaks Berkeley metafüüsilise põhipositsiooni, kuid kritiseeris selle kummastavat esitust. Mateeria olemasolu täielik eitamine on liig, leidis Leibniz. Selle asemel tuleks tema meelest öelda, et mateeria on fenomen, nähtumus, ehkki mitte substants (vt McCracken \& Tipton 2000: 191-192). Mõlemad filosoofid leidsid, et maailma fundamentaalseteks koostisosadeks on jagamatud mittemateriaalsed substantsid, mis tajuvad ja toimivad. Eri meelel olid nad aga selles, kui palju neid substantse on ja kuidas nad liigituvad. Leibnizi arvates on sääraseid substantse (ehk monaade) lõpmatult palju ning paljud neist on teadvuseta. Lisaks tegi ta vahet lihtsatel ja liitsetel substantsidel, nõnda et esimesed moodustavad teisi (vt Leibniz 2020: 302-305). Berkeley järgi on substantside hulk piiratud. Nagu peagi näeme, omistab ta substantsi staatuse vaid teadvuslikele, mõistuslikele tajujatele. 
Selgitamaks avalikkusele oma vaateid, avaldas Berkeley 1713. aastal "Kolm dialoogi Hylase ja Philonousi vahel". ${ }^{2}$ Lisaks "Traktaadis" väljendatud seisukohtade esitusele populaarsemas vormis sisaldab see hilisem teos üht uut põhjalikku arutelu, nimelt selle üle, kuidas klapib mateeria olemasolu eitamine kokku loomislooga Moosese 1. raamatus. Nagu me teame Berkeley kirjavahetusest tema sõbra, Sir John Percivaliga, püstitas vastava probleemi viimase abikaasa (vt Works 8: 37-38). ${ }^{3}$ Kristliku filosoofina püüdis Berkeley näidata, et tema filosoofia ja ilmutatud loomisloo vahel vastuolu pole. Sealjuures on tema argumentatsioon üsna peen ja pingutatud. Allpool näitan, et Berkeley tõlgendab loomislugu sõnasõnaliselt ning selle metafüüsilise eksegeesi käigus joonistub välja platonistlik skeem, mis osutub omakorda problemaatiliseks. Ühtlasi selgitan, kuidas selles arutelus ilmneb 18. sajandi alguse filosoofia keerukas suhe ilmutusreligiooniga.

\section{Idealism}

Berkeley idealistliku metafüüsika järgi koosneb maailm vaimudest (ingl mind, spirit) ehk mittemateriaalsetest substantsidest ja nende tajumustest ehk ideedest. Niisugune on tema positiivne programm nii "Traktaadis" kui "Kolmes dialoogis", mille ta mateeria olemasolu eitamise juures välja pakub. Ise nimetab ta oma õpetust "immaterialismiks" (Works 2: 255, 257, 259).

Berkeley arvates on alati eksisteerinud Jumal ehk igavene ja piiritu Vaim, kes on loonud hulga piiratud vaime. Viimaste all peab ta esmajoones silmas inimesi, kuid mõnedes kontekstides ja kirjutistes tulevad mängu ka inglid. Kõik nimetatud vaimud Berkeley süsteemis on teadvuslikud ja mõistuslikud. Inimvaimu nimetatakse ka hingeks ja minaks (ibid.: 41-42). Loomade staatus jääb siinkohal mõnevõrra ebaselgeks. Loomad on küll tajujad, kuid paistab, et lausa vaimu neile ei omistata (vt ibid.: 188-189).

Kõigi vaimude olemine seisneb tajumises ja toimimises. Vaimud ehk toimijad tajuvad ideid. Ideed asuvad vaimus. "Ideede" all peetakse siin silmas nii kujutlusi kui meelelisi tajumusi. "Traktaadis" sedastab Berkeley, et oma kujutluste üle on meil teatav voli niivõrd, kuivõrd me saame neid omatahtsi kombineerida. Kuid meeleliste tajumuste üle meil suuremas osas sellist meelevalda pole: nägemise, kuulmise ja teiste meeltega tajutavad värvid, kujud, liikumised jmt ideed ilmnevad meile valdavas osas nii, nagu nad ilmnevad. Samas moodustub ideedest, mida me meeltega tajume, korrapärane maailm. Berkeley arusaama järgi on selle korrapärase maailma loonud ja seda hoiab käigus Jumal, kes teatud reeglite ehk loodusseaduste järgi meie meeltele neid 
värve, kujusid, lõhnu, liikumisi ja nende erinevaid kombinatsioone esitab (vt Ibid.: 53-54).

Mateeriat ehk vaimust sõltumatut füüsilist maailma selles süsteemis ei ole. Füüsilised asjad ehk kehad eksisteerivad vaid niivõrd, kuivõrd mingi vaim neid tajub: kehad on ideekogumid, mida me meeltega tajume. Õun pole enamat kui teatud värvi, lõhna, kuju, maitse jt tajutavate omaduste kombinatsioon (Ibid.: 41). Ideede olemine seisneb nende tajutud-olemises. See vaade tekitab küsimuse, mis juhtub asjadega siis, kui me neid parasjagu ei taju. Kas maja ja puu lakkavad olemast, kui ükski inimene ega loom neid ei taju? Ja hakkavad uuesti olema, kui neid taas tajutakse?

Berkeley vastus neile küsimustele on kahetine. Esiteks selgitab ta, et kui me mõnda füüsilist asja või nähtust parasjagu ei taju, siis ometi eksisteerib see selles tingimuslikus mõttes, et kui me oleksime vastavas kohas, siis me seda ka tajuks. Sest Jumal on asjad niimoodi korraldanud. Sel kombel eksisteerib mu kirjutuslaud, mida ma parajasti ei näe, sest olen teises toas. Nii on korrektne väita ka nt seda, et Maa liigub - me ei taju seda siin ja praegu, kuid teatud kaugusel Maast tajuksime (vt Ibid.: 42, 65-66). Aga teiseks eksisteerivad füüsilised asjad ehk ideekogumid mingil moel ka Jumalas, seda ka siis, kui ükski piiratud vaim neid parasjagu ei taju (Ibid.: 43, 61, 212, 230-231).

\section{Realism ja fenomenalism}

See kahetine käsitus parasjagu tajumata asjade olemisest on saanud aluseks kahte sorti tõlgendustele. Ühe vaate järgi saab Berkeley filosoofia puhul rääkida realismist, teise järgi fenomenalismist. ${ }^{5}$ Mõlemal puhul peab silmas pidama, et kõne all on asjade olemisviis idealistliku metafüüsika raamistuses, kus eitatakse mateeria ehk tajumisest sõltumatu füüsilise maailma olemasolu.

Realismi all peetakse siin silmas naiivrealistlikku käsitust, mille järgi füüsiline maailm ongi enamvähem selline, nagu me seda meeltega tajume. Pilvedel on värvid, mida me neil olevat näeme, ja neil on värvid ka siis, kui me vaatame hoopis mujale. Pilved ise on teatud värvi. Kohvil on see maitse, mida me seda juues tunneme, ka siis, kui me parasjagu kohvi ei joo. See maitse on kohvi enda omadus. Meile tuttavad lõhnad, värvid, maitsed jmt omadused on asjadel päriselt ja teatud puhkudel me neid omadusi ka tajume. Tajume maailma oma meeltega vahetult ja enamasti korrektselt. ${ }^{6}$

Berkeley süsteemis tähendaks naiivrealism seda, et füüsilised asjad - säärastena, nagu me neid oma meeltega tajume - asuvad Jumalas ehk igaveses Vaimus. Sestpeale, kui Jumal selle meelelise maailma lõi, tajub ta seda pidevalt. Ka meil, piiratud vaimudel on sellele maailmale vahetu ligipääs. Asjad 
on ideekogumid, mida tajub Jumal ja tajume ka meie. Niisuguse tõlgenduse pooldaja oli kunagine kuulus Berkeley-uurija A. A. Luce (vt 1945: 120-125).

Berkeley meelest on asjad tõesti niisugused, nagu me neid tajume. Nad pole värvi, lõhna ja maitseta materiaalsed substantsid. Küsimus on aga selles, missugused või mis mõttes on asjad siis, kui me neid parasjagu ei taju. Berkeley väitel on nad siis (ja tegelikult kogu aeg) Jumalas. Kuid pole selge, missugused need asjad Jumala igaveses vaimus on - võib-olla teistsugused kui piiratud vaimudes. Realistliku tõlgenduse vastu räägib see, et asjad meelelises maailmas on pidevas muutumises ja ajalised, Jumal aga muutumatu ja ajatu. Lisaks on Berkeley väitnud, et Jumal teab kõike, kuid ta ei taju midagi meeltega, nagu meie seda teeme. Jumalal ei ole aistinguid (Works 2: 240-241). Neil asjaoludel on küsitav, kas naiivrealistlikult mõistetud maailma saab paigutada Jumala vaimu.

Fenomenalism on vaade, mille järgi füüsilised asjad ei eksisteeri iseeneses, vaid üksnes tajujate suhtes. Asjade olemasolu taandub meie asjassepuutuvatele - tegelikele ja võimalikele - tajumustele. Kohvitassid eksisteerivad kui meie tegelikud ja võimalikud kohvitassi-tajumused.

See käsitus klapib Berkeley väidetega selle kohta, mis mõttes eksisteerib mu kirjutuslaud, kui ma seda parasjagu ei taju, või mis mõttes toimub Maa liikumine (vt eelpool). Erinevalt sekulaarsest fenomenalismist on aga tema oletatava fenomenalismi järgi tajumuste põhjuseks Jumal, kes vastavalt enda seatud reeglitele tekitab meis erinevates olukordades erinevaid tajumusi (vt Stack 1969; McCracken 2008: 36). Ka selle tõlgenduse puhul peab arvestama Berkeley arusaamaga, et teataval igavikulisel kujul on meelelise maailma asjad siiski alati Jumala vaimus olnud. Seeläbi on nad ka midagi enamat kui meie võimalikud ja tegelikud tajumused.

\section{Lady Percivali vastuväide}

Mõnevõrra ootamatu nurga alt lähenes Berkeley “Traktaadile” tema sõbra, Sir John Percivali abikaasa, kes püstitas järgneva probleemi. Kui mateeriat ei ole olemas ning eksisteerivad vaid vaimud ja ideed, siis kuidas mõista seda osa loomisloost, mis kirjeldab sündmusi enne inimese loomist (vt Works 8: 37-38; McCracken \& Tipton 2000: 160-163)? Esimese Moosese raamatu järgi loodi taevas, maa ja meri ning mitmesugused taimed ja loomad ju enne inimesi ( $1 \mathrm{Ms} 1$ : 1-25). Viimased astuvad maailma alles kuuendal loomispäeval (1 Ms 1: 26-27).

Lady Percivali küsimus tõi Berkeley süsteemis esile lausa kaks probleemi, mis on seotud loomisega. Esiteks räägib loomislugu tegelike asjade, mitte kellegi vaimus esinevate ideede loomisest. Aga teiseks, kui mõista neid asju 
Berkeley kombel ideekogumitena, siis tundub, et taevas ja maa ei saa eksisteerida enne, kui on loodud inimvaimud, kes neid ideekogumeid tajuvad. Teisiti öeldes: objektid ei saa olla enne subjekte, sest objektide olemine seisneb selles, et subjektid neid tajuvad. Füüsiliste asjade loomine enne inimese loomist on seega sisutühi ja Berkeley filosoofia vastuolus ilmutusega.

Niisugune vastuväide ei tulnud Berkeley'le siiski päris üllatusena. Mateeria olemasolu eitamiseni jõudis ta juba oma varastes märkmetes ehk "Filosoofilistes kommentaarides" aastail 1707-1708. Sealjuures arutles ta mõnedes sissekannetes ka loomisloo üle ja nähtavasti mõtles ka selle võimaliku vastuväite peale, mille Lady Percival talle hiljem esitas. ${ }^{7}$ Sellegipoolest tõi just Lady Percival täie teravusega esile raskuse, mis tekib immaterialismi kooskõlastamisel loomislooga.

Berkeley pidas vajalikuks reageerida. Filosoofi ja anglikaani vaimulikuna võttis ta seda teemat kahtlemata tõsiselt, vastates kõigepealt eraviisiliselt, Sir Percivali vahendusel. Nagu mitmed teisedki Berkeley "Traktaadi" varased kriitikud, ei olnud Lady Percival teost lugenud, kuid erinevalt teistest kriitikutest pälvis ta Berkeley kiituse ja nimelt selle eest, et esitas oma vastuväite “mõistuse ja argumendi" toel (Works 8: 38). ${ }^{8}$ Mõne aasta pärast vastas Berkeley sellele kriitikale juba avalikult ja põhjalikult "Kolme dialoogi” lõpupoole, püüdes üksikasjalikult näidata, et tema filosoofia ei ole pühakirjaga vastuolus (Works 2: 250-256). ${ }^{9}$

\section{Hr Berkeley vastus}

Kuidas siis mõista füüsiliste asjade ehk kehade loomist Berkeley idealistlikest printsiipidest lähtudes? "Kolme dialoogi” kolmandas dialoogis selgitab Berkeley kõneisik Philonous kõigepealt, et tal pole kahtlustki, et meelelised asjad, nagu näiteks taevakehad ja taimed, tõepoolest eksisteerivad ning maailma alguses loodi. Kui ta nimetab neid asju "ideedeks", siis ei mõtle ta selle all inimvaimu sünnitisi ehk kujutlusi, vaid meeltega vahetult tajutud asju. Kas neid "ideedeks" nimetada või mitte, polegi oluline. Oluline on mõista, et asjad on säärased, nagu nad meile paistavad, ja et nad eksisteerivad vaimudes, mitte vaimudest sõltumatult. Just niisuguste, tõeliste asjade loomisest käib pühakirjas jutt, leiab Philonous. Piibli alguses ei räägita asjadest kui värvi ja lõhnata materiaalsetest substantsidest, mis eksisteerivad vaimudest sõltumatult. Niisiis on immaterialism loomislooga kooskõlas ning hoopis mateeria olemasolu postuleerivatel õpetustel pole pühakirjaga midagi pistmist (Works 2: 250-251, 255-256).

Edasi väidab Philonous, et asjad saavad alguse ehk luuakse piiratud vaimude, mitte Jumala enese suhtes. Jumal teab ehk tema vaim sisaldab kõiki asju 
igavesti. Loomine seisneb selles, et asjad, mis Jumalale on alati teada olnud, muudetakse tema korralduse (ingl decree) läbi tajutavaks (ingl perceptible) ka piiratud vaimude jaoks (Ibid.: 251-253).

Kuidas sai Jumal luua taeva, maa ja palju muudki enne, kui ta lõi inimvaimud, kelle tajuobjektidena asjad eksisteerivad? Vastuseks Lady Percivali püstitatud probleemile osutab Philonous esmalt sellele, et juba enne inimvaime võisid asjade loomist tajuda "teised loodud intellektid" ehk teised "piiratud loodud vaimud" (Ibid.: 252). Kirjas Sir Percivalile ütleb Berkeley otsesõnu, et ta peab siin silmas ingleid, kelle olemasolu kinnitavad nii mõistus kui pühakiri (Works 8: 37-38).

Philonous jätkab kujutluspildiga kõrbest, kus nähtamatu vägi tekitab igasuguseid taimi. Ühtegi piiratud vaimu ses kõrbes ei ole, kuid loomine toimub. See pilt olevat tema (ehk Berkeley) õpetusega kooskõlas (Works 2: 252). Päris ilmne see kooskõla pole. Nagu Philonous eelpool selgitas, seisneb füüsiliste asjade loomine selles, et Jumala korralduse läbi muutuvad asjad, mis seni eksisteerisid oma igavikulisel kujul Jumala vaimus, potentsiaalselt tajutavaks ka piiratud vaimude jaoks. Seejärel luuakse vaimud, kes asju tegelikult tajuma hakkavad. Tundub, et nimetatud korralduse andmine on midagi muud kui asjade tekitamine kõrbes, kus pole ühtegi loodud tajujat. Philonousi sõnul näitab see pilt kõigi asjade sõltuvust Jumalast (Ibid.). Kuid see pilt näikse viitavat ka sellele, et Jumal ise tajub mingil viisil neid taimi, mis ta tühjas kõrbes loob, ja tajub kogu kõrbe, sest kui ta neid asju ses olukorras ei tajuks, siis neid ei oleks. Kui aga Jumal neid ajas loodavaid asju tajub, siis paistab, et nende loomine toimub ka Jumala enese, mitte üksnes piiratud vaimude suhtes ja see räägib vastu seisukohale, mida Philonous eelpool väljendas.

Kui Philonousi oponent Hylas nõuab selgitust selle kohta, kas Jumal andis kõnealuse loomiskorralduse igavikuliselt või mingil kindlal ajal, siis Philonous vastab, et meie ei suuda loomist ette kujutada teisiti kui ajas toimununa, kuid üleloomuliku ja täiusliku Jumala, tema omaduste ja toimimisviiside täpsem mõistmine käib meil üle jõu (Ibid.: 254).

Kokkuvõttes eristab Berkeley Philonousi suu läbi kahesugust asjade korda: asjad eksisteerivad (1) igavesti oma arhetüüpsel kujul, muutumatute ideedena Jumala vaimus ning (2) loomisjärgsel, ektüüpsel kujul, muutlike ideekogumitena piiratud vaimudes (Ibid.). Teisiti öeldes: Jumala vaimus on originaalid, piiratud vaimudes koopiad. Sellist platonistlikku skeemi me Berkeley “Traktaadis" ei näe. Tolles varasemas teoses sisaldub küll väide, et meelelised asjad eksisteerivad mitte üksnes meie, vaid ka Jumala vaimus, kuid lähemalt nende kahe olemisviisi vahekorda ei selgitata.

Niisiis esitas Berkeley Lady Percivali kriitikast ajendatuna võrdlemisi keeruka metafüüsilise konstruktsiooni, milles maailma loomise akt osutub 
Jumala korralduseks tekitada potentsiaalsetes tajujates reeglipärasel moel teatud sorti tajumusi. Üldjoontes paistab, et fenomenalistlik tõlgendus sobib selle konstruktsiooniga paremini kokku kui naiivrealistlik, sest viimase puhul tuleks arhetüüpidele lisaks paigutada Jumala vaimu ka ektüübid, mis tunduvad seal liiased olevat. Fenomenalistliku käsituse järgi eksisteerivad meelelised asjad inimvaimude potentsiaalsete ja tegelike tajumustena. Maailma luues seab Jumal sisse korra, mille järgi ta neid tajumusi tekitab. Siiski tekib mõlema tõlgenduse puhul raskusi teatud kirjakohtadega "Kolmes dialoogis". ${ }^{10}$

Berkeley küll vastas üksikasjalikult Lady Percivali vastuväitele, ent platonistlik skeem selles vastuses jäi mõneti ebaselgeks. Aastail 1729-1730 nõudis temalt arhetüüpide ja ektüüpide kohta selgitusi Ameerika filosoof Samuel Johnson (1696-1772). Kirjavahetuses uurib Johnson, kas Berkeley meelest on Jumala vaimus puu idee (või puu), mis on meie poolt tajutud erinevate puu-ideede (ehk puude) arhetüüp. Johnson räägib tervest asjade või ideede "süsteemist" Jumala vaimus (vt Works 2: 272-273, 285-286). Berkeley vastab lühidalt, et tal pole midagi selle vastu, et Jumala vaimus asuvaid ideid nimetada meie ideede arhetüüpideks, peaasi, et nende all ei peeta silmas materiaalseid asju, mis eksisteerivad vaimudest sõltumatult (Works 2: 292). Jääb mulje, et täpsemaid selgitusi Berkeley siinkohal anda ei taha. Ühest küljest väidab ta oma filosoofias, et meeltega tajumatud materiaalsed asjad on meie tajumuste seletamisel üleliigsed: Jumal tekitab meis tajumusi vahetult. Teisest küljest väidab ta, et meeltega tajutud asjadele ehk ideekogumitele vastavad siiski mingid arhetüübid Jumalas, mis on meie jaoks tajumatud. Tekib hulk küsimusi. Kuidas me teame, et säärased arhetüübid olemas on? Kas nende olemasolu on tarvis postuleerida? Kuidas need arhetüübid omavahel suhestuvad? Mida nad õieti endast kujutavad? Berkeley ei paku selgepiirilisi vastuseid. ${ }^{11}$

\section{Järeldused}

Esiteks tundub, et just Lady Percivali religioosse vastuväite ajel toob Berkeley kirjasõnas välja oma platonistliku skeemi, mis teataval määral selgitab meeltega tajutavate asjade ja Jumala igavikuliste ideede vahekorda. Näeme, kuidas ilmutusreligioon sekkub jõuliselt metafüüsikasse ja sellel on konkreetsed filosoofilised tagajärjed. Just "Kolmes dialoogis" ilmneb, et ajalikud asjad ehk ideekogumid meie vaimudes on igaveste, Jumala vaimus asuvate originaalide koopiad.

Teiseks, Berkeley tõlgendab loomislugu ühtaegu filosoofiliselt ja sõnasõnaliselt, käsitledes Esimese Moosese raamatu algust kosmoloogilise tõe allikana. Vähemalt üldjoontes jääb ta piibelliku kirjelduse juurde, milles asjade ja 
olendite loomine toimub kindlas järjekorras. Paraku saab probleemiks just see järjekord, sest tema idealistliku süsteemi kohaselt ei saa asjad eksisteerida enne tajujaid ega üldse, ilma et keegi neid tajuks. Lahenduseks pakutav metafüüsiline konstruktsioon mõjub küllaltki kunstlikult, mis näitab, kui kaugele oli autor valmis minema, et näidata oma filosoofia kooskõla pühakirjaga.

Kolmandaks, 18. sajandi alguse Euroopas ei ole filosoofia (sealhulgas natuurfilosoofia) veel teoloogiast täielikult eraldunud. Küsimus ei olnud ainult Jumala kaalukas rollis filosoofide süsteemides ja skeemides, vaid ka piibli jätkuvas autoriteedis kosmoloogiliste, ajalooliste jmt küsimuste teoreetilisel käsitlemisel.

\section{Kommentaarid}

1 Ülevaate varastest reaktsioonidest Berkeley filosoofiale annab McCracken \& Tipton 2000: 159-190.

2 Ilmunud ka eestikeelses tõlkes: Berkeley 1997. Nimesid "Hylas" ja "Philonous" võiks sisuliselt tõlkida sõnadega "materialist" ja "mõistusearmastaja".

3 Berkeley teoste standardväljaandele (1948-57, lüh Works) viidates tsiteerin köite ja lehekülje numbrit.

4 Berkeley ei erista selgepiiriliselt tajumise akti ja objekti.

5 Nüüdisaegsete teooriate omistamine filosoofia ajaloo suurkujudele on kindlasti problemaatiline. Vt selle kohta lähemalt Jakapi 202Oa.

6 Mittenaiivse realismi järgi eksisteerib füüsiline maailm tajumisest sõltumatult ega sisalda maitseid, värve, lõhnu jt sedasorti omadusi niisugusel kujul, nagu me neid meeltega tajume.

7 Täpsemalt on loomine vaatluse all selle käsikirja sissekannetes $\mathrm{nr}$ 60, 293, 339, 436 ja 723. Vt Works 1: 13, 36, 41, 54, 88.

8 Selle info põhjal võiks siis ehk ka Lady Percivali lugeda 18. sajandi naisfilosoofide hulka. Viimaste ideid kajastab Broad 2020.

9 Nõue püsida kooskõlas pühakirjas ilmutatuga oli varauusaegse filosoofi jaoks loomulik. See käib ka tollaste natuurfilosoofide, näiteks Robert Boyle'i (1627-1691), Sir Isaac Newtoni (1642-1727) ja William Whistoni (1667-1752) kohta. Need protestantidest looduseuurijad olid ühtlasi innukad eksegeedid, kelle arvates sisaldab piibel nii eshatoloogilist kui kosmoloogilist teavet, mida tuleb oma seisukohtade kujundamisel arvesse või lausa eelduseks võtta. Whiston esitas ka loomisloo üksikasjaliku natuurfilosoofilise käsituse, milles Jumal teostab oma plaane erinevaid loodusprotsesse juhtides (vt Jakapi 2020b). Mõistagi eeldas säärane loomise kirjeldus mateeria olemasolu. Whiston nimetas Berkeley filosoofia põhijäreldust, et mateeriat pole olemas, absurdseks (vt McCracken \& Tipton 2000: 163). Samal ajal astusid aga esile niisugused vabamõtlejad nagu John Toland (1670-1722) ja Anthony Collins (1676-1729), kes õonestasid ilmutusreligiooni aluseid nii teoloogiliste kui ka filosoofiliste argumentide abil ja seadsid pühakirja autoriteedi kahtluse alla. Berkeley eitas küll mateeria olemasolu, kuid seisis kindlalt ilmutusreligiooni kaitsvate filosoofide leeris, vaieldes vabamõtlejatele põhjalikult vastu oma 1732. aastal ilmunud teoses "Alciphron" (Works 3). 
${ }^{10}$ Loodud füüsilise maailma olemisviisi probleemi lahendamine Berkeley süsteemi kontekstis ei ole selle artikli eesmärgiks. Asjakohast arutelu pakub Stoneham 2002: 168-176, 282-291.

${ }^{11}$ Põhjalikult arutleb arhetüüpide üle Frankel 2016.

\section{Kirjandus}

Works $=$ Berkeley, George 1948-57. The Works of George Berkeley Bishop of Cloyne. 9 vols. Luce, A. A. \& Jessop, T. E. (toim). London: Thomas Nelson.

Berkeley, George 1997. Kolm dialoogi Hylase ja Philonouse vahel. Jakapi, Roomet (tlk). Akadeemia 8-11, lk 1765-1789, 1983-2013, 2209-2237, 2433-2453.

Broad, Jacqueline (toim) 2020. Women Philosophers of Eighteenth-Century England. Selected Correspondence. Oxford New Histories of Philosophy. New York: Oxford University Press.

Frankel, Melissa 2016. Berkeley on the "Twofold state of things". International Journal for Philosophy of Religion 80, lk 43-60 (DOI: 10.1007/s11153-015-9541-2).

Jakapi, Roomet 2020a. Filosoofia ajaloo uurimisest angloameerika traditsioonis G. Berkeley vaadete käsitlemise näitel. Studia Philosophica Estonica 13. Filosoofia ajalugu: meetodid ja praktikad.

Jakapi, Roomet 2020b. Early modern natural philosophy allied with revealed religion: Boyle and Whiston. Fuller, Michael \& Evers, Dirk \& Runehov, Anne \& Sæther, KnutWilly \& Michollet, Bernard (toim). Issues in Science and Theology: Nature-And Beyond. Transcendence and Immanence in Science and Religion. Springer, lk 233-243 (DOI: 10.1007/978-3-030-31182-7_19).

Leibniz, Gottfried Wilhelm 2020. Valitud kirjad ja tööd. Ott, Margus (tlk). Tartu: Ilmamaa.

Luce, A. A. 1945. Berkeley's Immaterialism: A Commentary on his "A Treatise Concerning the Principles of Human Knowledge”. London \& Edinburgh \& Paris \& Melbourne $\&$ Toronto \& New York: Thomas Nelson \& Sons.

McCracken, Charles J. \& Tipton, Ian C. (toim) 2000. Berkeley's Principles and Dialogues. Background Source Materials. Cambridge Philosophical Texts in Context. Cambridge: Cambridge University Press.

McCracken, Charles J. 2008. Berkeley's Realism. Daniel, Stephen H. (toim). New Interpretations of Berkeley's Thought. Amherst, NY: Humanity Books, lk 23-44.

Piibel 2000. Tallinn: Eesti Piibliselts.

Stack, George J. 1969. Berkeley's Phenomenalism. The Personalist 50, lk 335-359.

Stoneham, Tom 2002. Berkeley's World: An Examination of the Three Dialogues. Oxford: Oxford University Press. 


\title{
Summary
}

\section{The Creation Story in Philosophy: Mr Berkeley's Response to Lady Percival}

\author{
Roomet Jakapi \\ Associate Professor of History of Philosophy \\ University of Tartu \\ roomet.jakapi@ut.ee
}

Keywords: Berkeley, history of philosophy, revealed religion, the Creation story, early modern period

The paper discusses George Berkeley's metaphysical account of the Creation in his work Three Dialogues Between Hylas and Philonous (1713). As we know from Berkeley's correspondence, his detailed attempt to show that his immaterialist philosophy is compatible with the Mosaic description of the Creation was occasioned by an objection from the wife of his friend Sir John Percival.

According to Berkeley's philosophy, only minds and ideas exist. Physical things such as books and trees are mere collections of ideas in human minds. No thing can exist unless there is a mind to perceive it. Yet the Mosaic story states that many things were created and existed before humans came into being. Lady Percival pointed out that Berkeley's view makes it hard to understand how things could be created if there were no human beings around to perceive them.

In response, Berkeley offered a sophisticated metaphysical construct in which the creation of the physical world is interpreted as God's decree to produce certain kinds of ideas in potential perceivers.

The paper aims to show how Berkeley's response to Lady Percival's objection reflects the complicated relationship between philosophy and revealed religion in the early 18th century. Berkeley's commitment to biblical truth sets significant limits to his philosophical speculation.

Roomet Jakapi on Tartu Ülikooli filosoofia ajaloo kaasprofessor. Tema peamised uurimis- ja õpetamisvaldkonnad on varauusaegne filosoofia ja analüütiline religioonifilosoofia.

Roomet Jakapi is Associate Professor of History of Philosophy at the University of Tartu. His main fields of research and teaching are early modern philosophy and analytic philosophy of religion.

roomet.jakapi@ut.ee 